\title{
A parasite indirectly impacts both abundance of primary producers and biomass of secondary producers in an intertidal benthic community
}

\author{
Kim N. Mouritsen ${ }^{\ddagger}$ and Robert Poulin ${ }^{\dagger}$ \\ *Department of Marine Ecology, Institute of Biological Sciences, Aarhus University, Finlandsgade 14, DK-8200 Aarhus N, Denmark. \\ ${ }^{\dagger}$ Department of Zoology, University of Otago, PO Box 56, Dunedin, New Zealand. \\ ${ }^{\ddagger}$ Corresponding author, e-mail: kim.mouritsen@biology.au.dk
}

The New Zealand cockle Austrovenus stutchburyi is often found stranded on the sediment surface due to infections by echinostome trematodes. High densities of heavily-infected cockles on the sediment surface affect near-seabed hydrodynamics and sedimentation and, in turn, benthic animal community structure and diversity. In a six-month field experiment on an intertidal sandflat we manipulated the density of cockle mimics on the sediment surface, and here we show that their presence had two significant impacts on community functioning. First, the benthic primary production (in terms of chlorophyll- $a$ content) was reduced by $8-22 \%$. Second, their presence significantly boosted (up to 5-fold) the secondary production (in terms of biomass) of Coelenterata, Nemertea, small polychaetes, small bivalves and the gastropod Diloma subrostrata. The results hence provide a field experimental example of a parasite-mediated link between diversity and productivity.

\section{INTRODUCTION}

One of the most active and controversial research areas in ecology over the last few years has been the study of the relationship between biodiversity and ecosystem functioning, in particular the link between diversity and ecosystem productivity (e.g. Loreau et al., 2001; Naeem \& Wright, 2003). The consensus that is slowly emerging is that species diversity influences productivity, as well as other fundamental ecosystem properties such as stability (e.g. McCann, 2000; Fridley, 2001), although exactly how it does so remains unclear. In this context, field manipulations that allow differences in local diversity to develop naturally can shed light on how diversity impacts on productivity.

Parasitism is increasingly recognized as a factor that can determine the diversity and structure of animal communities (Minchella \& Scott, 1991; Thomas et al., 1998; Mouritsen \& Poulin, 2002). Intuitively, one might expect that parasitism would have a negative impact on diversity, but this is not so. For instance, two echinostome trematodes parasitize the common cockle Austrovenus stutchburyi, the most important invertebrate in terms of biomass on New Zealand intertidal soft-bottom habitats. The two parasites, Curtuteria australis and Acanthoparyphium sp., can attain high infection levels in cockles, and combine to interfere with the mobility and burrowing ability of their cockle hosts (Thomas \& Poulin, 1998; Mouritsen, 2002; Babirat et al., 2004). They encyst in the cockle's foot and impair its function to the point that severely infected cockles remain stranded at the sediment surface for an extended period of time. Previously, we have shown that both the reduced movement (bioturbation) of cockles and the greater density of surfaced cockle mimics result in increased species richness and higher densities of most taxa and functional groups of macroinvertebrates in the benthic community (Mouritsen \& Poulin, 2005). Solely through their effect on cockle behaviour, these parasites cause changes in the structural complexity of the sediment surface, in the near-seabed hydrodynamics, and in small-scale sedimentation patterns, with cascading effects on the biotic community. Such trait-mediated indirect effects of parasitism can generate variation in community diversity among different localities, since infection levels by echinostome trematodes in cockles vary greatly on a regional scale (Mouritsen \& Poulin, unpublished data). It is not clear, however, how this parasiteinduced variation in local diversity translates into variation in key system properties such as productivity.

Here, we extend our investigation into this system by quantifying the simulated indirect impact of the parasites on primary and secondary production on New Zealand mudflats. Our specific objective is to assess alone the physical effect of increasing densities of heavily-parasitized surface cockles, here in terms of cockle mimics, on the abundance of primary producers and the biomass of secondary producers. These results can then be matched with our earlier demonstration that parasitism in this system increases species richness and diversity, to evaluate the overall impact of the parasites on ecosystem functioning.

\section{MATERIALS AND METHODS}

Study site and experimental procedure

The experiment was carried out during the austral summer (November 2001 to May 2002) on the lower intertidal level ( $2 \mathrm{~h}$ exposure) of Gills Corner sand flat, Otago Harbour, South Island, New Zealand $\left(45^{\circ} 50^{\prime} \mathrm{S} 170^{\circ} 40^{\prime} \mathrm{E}\right)$. 
Here the infection intensity by echinostomes in local bivalves is relatively low and surfaced cockles are rarely found. The experiment was carried out as a randomized block design in which three treatments manipulating the density of cockle mimics on the sediment surface, and hence their impact on near-seabed hydrodynamics and sedimentary conditions (see Mouritsen \& Poulin, 2005), were randomized within seven blocks distributed evenly along a $56 \mathrm{~m}$ transect parallel to the waterline.

The experimental unit was a $1 \times 1 \mathrm{~m}$ plot crossed by ten parallel fishing-lines attached to peripheral lines anchored into the sediment by pegs. The treatments were respectively none, 30 and 100 mimics attached to the parallel lines of the three experimental plots within each block. At sites of heavy infections, the natural densities of surfaced cockles may exceed $50 \mathrm{~m}^{-2}$, and thus the experimental densities we used cover the gamut of possibilities. The mimics were natural cockleshells glued shut (with clay enclosed to obtain approximately natural buoyancy) and attached to $6-\mathrm{cm}$ fishing-lines that in turn were attached to the parallel fishing-lines in a random pattern. The corner-pegs were hammered down below the sediment surface and the parallel fishing-lines were gently pushed into the substrate. This left no other part of the experimental set-up but the cockles (if present) on the surface. The use of anchored cockles was necessary to maintain the experimental densities of surfaced cockles throughout the duration of the experiment. Mean length $( \pm \mathrm{SE})$ of experimental cockles was $31.2 \pm 0.3 \mathrm{~mm} \quad(\mathrm{~N}=50)$. The number of live, buried cockles in each experimental plot was approximately 550, with no significant difference between treatments $\left(F_{2,102}=0.38, P=0.67\right)$.

After six months, we took five 15-cm deep core-samples (each $0.012 \mathrm{~m}^{2}$ ) in each treatment-plot and sieved them separately on a $500-\mu \mathrm{m}$ screen. All animals retained were preserved in $4 \%$ formaldehyde and identified to the lowest taxonomical level possible under a dissection microscope. In addition, five 5-cm deep sediment-cores (diameter= $4 \mathrm{~cm}$ ) were collected in each plot for analysis of the abundance of microphytobenthos.

\section{Abundance of primary producers}

The abundance of microphytobenthos in the substrate (largely epipelic and episammic diatoms) was estimated on the basis of chlorophyll- $a$ measurement in each sediment core-sample separately. Ten grams of well-mixed sediment was added to $40 \mathrm{ml} \mathrm{95 \%} \mathrm{ethanol} \mathrm{in} \mathrm{aluminium-}$ foil covered flasks, and left in a thermobath with a shaker at $20^{\circ} \mathrm{C}$ for $15 \mathrm{~h}$. The resulting solution was pipetted into a test tube and centrifuged at $3250 \mathrm{rpm}$ for $5 \mathrm{~min}$. The supernatant was then pipetted into $1 \mathrm{~cm}$ spectrophotometer cuvettes, and the absorbance at 750 and $664 \mathrm{~nm}$ was measured both before and after addition of acid (2M HCL). The chlorophyll- $a$ concentration $\left(\mathrm{mg} \mathrm{l}^{-1}\right)$ was then calculated according to the formula:

$[$ Chlorophyll- $a]=26.7\left(\mathrm{~A}_{\text {before }}-\mathrm{A}_{\mathrm{after}}\right)$

where $\mathrm{A}_{\text {before }}$ and $\mathrm{A}_{\text {after }}$ is the difference between the absorbance at 664 and $750 \mathrm{~nm}$ before and after addition of acid, respectively. This formula corrects for phaephytin- $a$ content and the values obtained therefore represent
Table 1. The nine categories of benthic animals, and the species or species groups they include, used in the biomass measurements. Numbers in parentheses denote the total number of species included in the category.

\begin{tabular}{|c|c|}
\hline Animal category & Species/species groups \\
\hline 1. Coelenterata (3) & $\begin{array}{l}\text { Anthopleura aureoradiata } \\
\text { Edwardsia spp. }\end{array}$ \\
\hline 2. Nemertea (6) & $\begin{array}{l}\text { Class: Anopla spp. } \\
\text { Class: Enopla spp. }\end{array}$ \\
\hline 3. Small polychaetes (13) & $\begin{array}{l}\text { Capitellidae spp. } \\
\text { Paraonidae sp. } \\
\text { Dorvillea incerta } \\
\text { Hesionidae sp. } \\
\text { Syllidae spp. } \\
\text { Exogone heterosetosa } \\
\text { Exogone sp. } \\
\text { Sphaerodorum sp. } \\
\text { Malococeros sp. }\end{array}$ \\
\hline 4. Large polychaetes (17) & $\begin{array}{l}\text { Abarenicola affinis } \\
\text { Heteromastus filiformis } \\
\text { Decamastus sp. } \\
\text { Travisia } \text { sp. } \\
\text { Armandia sp. } \\
\text { Scoloplos johnstonei } \\
\text { Macroclymenella stewartensis } \\
\text { Goniadidae sp. } \\
\text { Geminosyllis sp. } \\
\text { Aglaophamus sp. } \\
\text { Perinereis nuntia } \\
\text { Spio spp. } \\
\text { Boccardia syrtis } \\
\text { Prinospio sp. } \\
\text { Aonides sp. } \\
\text { Terebellidae sp. }\end{array}$ \\
\hline 5. Small crustaceans (15) & $\begin{array}{l}\text { Colurostylis lemurum } \\
\text { C. pseudocuma } \\
\text { Diastylopsis thileniusi } \\
\text { Order: Cyclopoida spp. } \\
\text { Order: Tanaidacea sp. } \\
\text { Heterophoxus stephenseni } \\
\text { Phoxocephalus regium } \\
\text { Pontharpinia australis } \\
\text { Haustoriidae sp. } \\
\text { Order: Amphipoda sp. } \\
\text { Eusirus sp. } \\
\text { Cymodopsis montis } \\
\text { Isocladus armatus }\end{array}$ \\
\hline 6. Large crustaceans (5) & $\begin{array}{l}\text { Nebaliidae sp. } \\
\text { Callianassa filholi } \\
\text { Macrophthalmus hirtipes } \\
\text { Pontophilus australis } \\
\text { Heterosquilla tricarinata }\end{array}$ \\
\hline 7. Small gastropods (4) & $\begin{array}{l}\text { Notoacmea helmsi } \\
\text { Micrelenchus huttoni } \\
\text { Pyramidellidae sp. } \\
\text { Neoguraleus sp. }\end{array}$ \\
\hline $\begin{array}{l}\text { 8. Large gastropods } \\
\text { (Trocidae) (1) }\end{array}$ & Diloma subrostrata \\
\hline 9. Small bivalves (7) & $\begin{array}{l}\text { Nucula dunedinensis } \\
\text { Perrierina turneri } \\
\text { Macomona liliana (juv.) } \\
\text { Austrovenus stutchburyi (juv.) } \\
\text { Order: Pelecypoda spp. } \\
\text { Solemys parkinsoni (juv.) }\end{array}$ \\
\hline
\end{tabular}




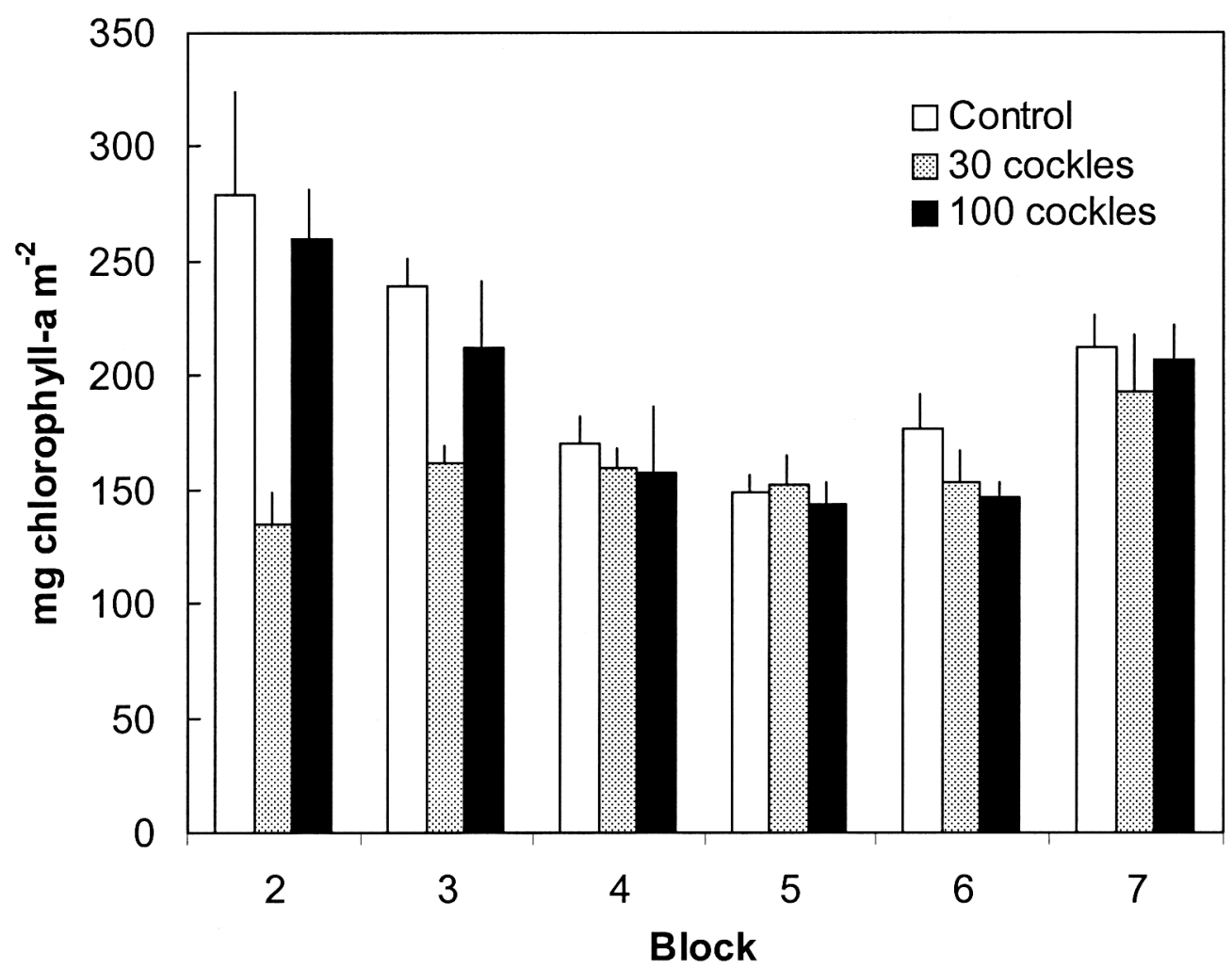

Figure 1. The abundance of benthic diatoms in terms of mean $( \pm \mathrm{SE}) \mathrm{mg}$ chlorophyll- $a \mathrm{~m}^{-2}$ along the experimental transect (block) for each of the three treatments. Control: no cockle mimics on the surface; 30 cockles: 30 mimics $\mathrm{m}^{-2}$ on the surface; 100-cockles: 100 mimics $\mathrm{m}^{-2}$ on the surface. $\mathrm{N}=5$ for all values.

'active' chlorophyll- $a$ that in surface samples of intertidal mud flats is a good estimator of the population of benthic diatoms and in turn autotrophic production (see Admiraal, 1984; Mouritsen et al., 1998). The chlorophyll- $a$ concentrations were converted into $\mathrm{mg} \mathrm{m}^{-2}$ units prior to statistical analysis.

\section{Biomass of secondary producers}

For each replicate core sample, animals were grouped into nine categories according to taxonomic affinity and size (see Table 1). Three remaining categories, large gastropods (Buccinidae), Echinodermata and Chordata (Pleuronectiformes), were excluded from the analysis due to their very infrequent occurrence in the samples. The dry weight (DW) and subsequently ash-free dry-weight (AFDW) was determined for each category separately following heating at $110^{\circ} \mathrm{C}$ for $14 \mathrm{~h}$ and $510^{\circ} \mathrm{C}$ for $16 \mathrm{~h}$, respectively.

\section{Data analysis}

The experimental design allowed a two-way analysis of variance (ANOVA) evaluating the effect of treatment, block and their interaction in one analysis. However, in all but two cases (biomass of small polychaetes and organic content) homogeneity of error variance could not be achieved even following standard transformations. Thus, in most cases the block effects (i.e. horizontal variation along the experimental transect) and block-treatment interactions were evaluated by treatment-wise KruskalWallis test or one-way ANOVA, depending on the nature of the data. Subsequent analyses of treatment effects were carried out on experimental-plot means with blocks as replicates. In the absence of block effect or large erratic horizontal variation for all three treatments (which otherwise would make an across-block comparison of the treatment level less powerful), Kruskal-Wallis tests and associated post-hoc tests were used. In the presence of block effect or relatively large erratic horizontal variation in one or more treatments, pair-wise comparisons of treatments were performed by Wilcoxon signed rank tests. The statistical analyses were carried out in the Statistical Package for the Social Sciences version 10.0, but for posthoc tests after a Kruskal-Wallis test we followed Siegel \& Castellan (1988). Two-tailed 5\% significance level is used throughout. Data on chlorophyll- $a$ from block 1 were excluded from the analysis because sediment samples in this block were collected by a corer with different dimensions from the one used for the remaining sediment samples.

\section{RESULTS}

\section{Abundance of primary producers}

The chlorophyll- $a$ content in the sediment of control and 100-cockle treatments showed significant spatial variation, with a parallel, approximately U-shaped pattern along the experimental transect (Figure 1; control: Kruskal-Wallis test, $\chi^{2}{ }_{[5]}=14.86, P=0.011 ; 100$ cockle treatment: Kruskal-Wallis test, $\chi_{[5]}^{2}=16.92$, $P=0.005)$. In contrast, no significant block-effect could be demonstrated in the 30-cockle treatment (Figure 1; oneway ANOVA, $F_{5,24}=1.72, P=0.17$ ), indicating a significant treatment-block interaction. Pair-wise comparisons of the three treatments showed a generally higher chlorophyll- $a$ 

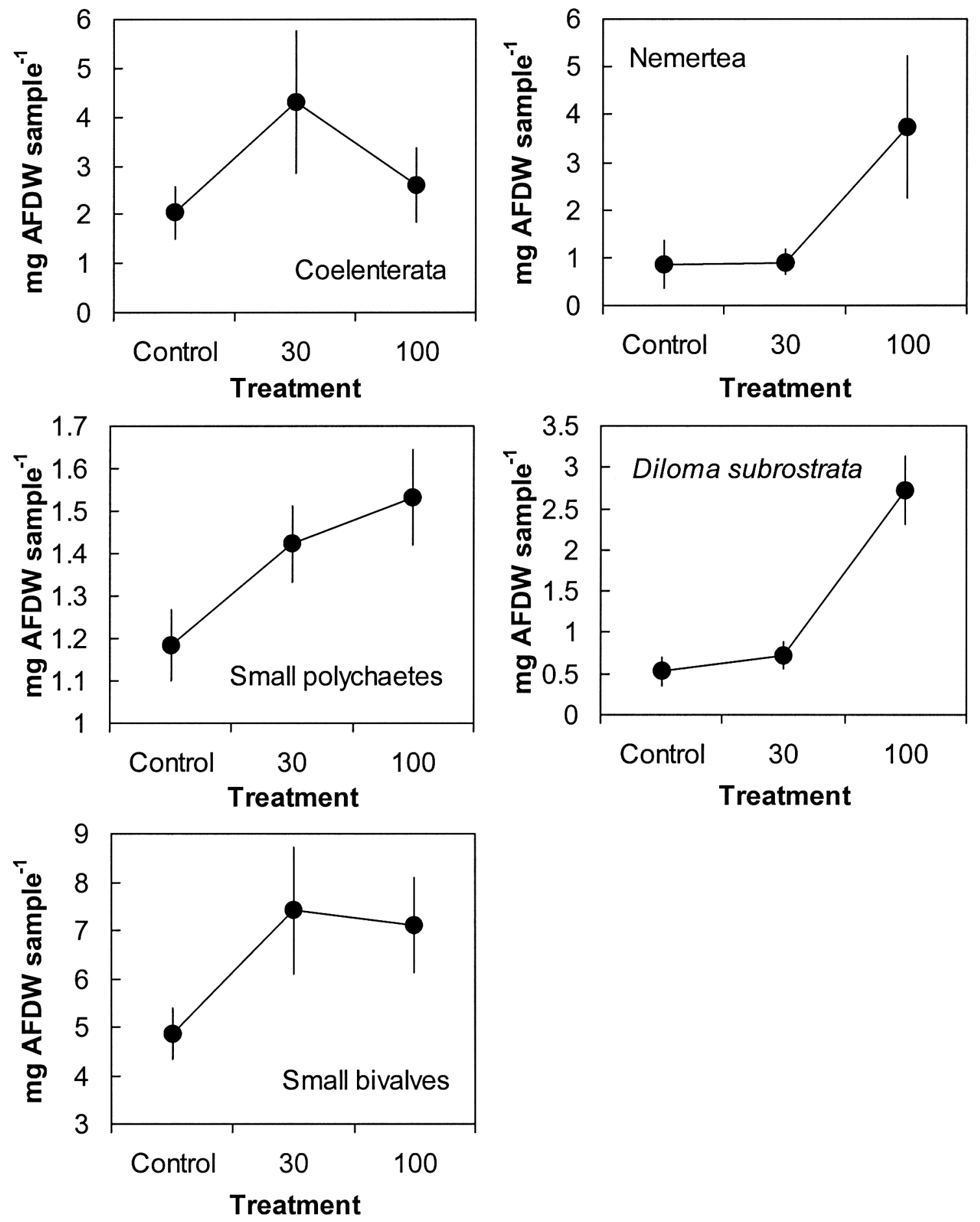

Figure 2. The mean biomass ( $\mathrm{mg}$ ash-free dry weight (AFDW) sample ${ }^{-1} \pm \mathrm{SE}$ ) of Coelenterata, Nemertea, Diloma subrostrata (Gastropoda), small bivalves and small polychaetes as a function of treatment (control: no cockle mimics on the surface; 30 : 30 mimics $\mathrm{m}^{-2}$ on the surface; 100: 100 mimics $\mathrm{m}^{-2}$ on the surface). Values are block-means $(\mathrm{N}=7)$ of experimental plot means $(\mathrm{N}=5)$.

level among controls (grand mean: $204.3 \mathrm{mg} \mathrm{m}^{-2}$ ) than in both the 30 -cockle $\left(158.9 \mathrm{mg} \mathrm{m}^{-2}\right.$ ) (Wilcoxon signed rank test, $Z=1.99, P=0.046)$ and the 100 -cockle treatment $\left(187.4 \mathrm{mg} \mathrm{m}^{-2}\right.$ ) (Wilcoxon signed rank test, $Z=2.20$, $P=0.028)$. The two cockle-treatments did not differ significantly (Wilcoxon signed rank test, $Z=0.94, P=0.35$ ).

\section{Biomass of secondary producers}

For all nine animal categories, a statistically significant block effect was absent. Five categories (Coelenterata,
Nemertea, small polychaetes, Diloma subrostrata [Gastropoda], and small bivalves) were significantly affected by treatments (Figure 2). The biomass of Coelenterata tended to peak at intermediate densities of surfaced cockle mimics, being significantly higher than the control (Wilcoxon signed rank test, $Z=2.03$, $P=0.043$ ), but not significantly different from the 100 -cockle treatment (Wilcoxon signed rank test, $Z=1.35, P=0.18$ ). Also the control and the 100-cockle treatment did not differ (Wilcoxon signed rank test, $Z=0.68, P=0.50$ ). The biomass of Nemertea peaked at the highest density of surfaced mimics (Kruskal-Wallis test, $\chi^{2}{ }_{[2]}=8.17, P=0.017$ ) being significantly 
higher than the biomass in both control $(P=0.018)$ and 30 cockle treatments $(P=0.035)$. The control and 30 -cockle treatments had similar biomass levels $(P=0.11)$. A full model twoway ANOVA on the biomass of small polychaetes showed no significant treatment-block interaction $\quad\left(F_{12,84}=0.94\right.$, $P=0.52)$. The subsequent reduced model demonstrated no block-effect $\left(F_{6,96}=1.10, P=0.37\right)$, but a significant effect of treatment $\left(F_{2,96}=3.42, P=0.037\right)$, where the biomass increased with increasing density of mimics on the surface (Figure 2). However, only the control and the 100-cockle treatment differed significantly (least significant difference post hoc test, $P=0.012$ ). The biomass of Diloma subrostrata was affected by treatments as in Nemertea (Kruskal-Wallis test, $\chi_{[2]}^{2}=13.78$, $P=0.001$, with a peak-level in the 100 -cockle treatment significantly higher than in the control $(P=0.02)$ and the 30 -cockle treatment $(P=0.02)$. The latter two treatments did not differ $(P=0.34)$. Whereas the biomass of small bivalves among controls was significantly lower than among 100-cockle treatments (Wilcoxon signed rank test, $Z=2.03, P=0.043$ ), there was no significant difference between the control and 30 cockle treatments (Wilcoxon signed rank test, $z=1.69$, $P=0.091$ ), nor between the two cockle treatments (Wilcoxon signed rank test, $Z=0.17, P=0.87$ ).

\section{DISGUSSION}

Assuming that the physical effect of cockle mimics is similar to that of heavily infected live cockles, the present results show that the occurrence of cockles on the sediment surface due to parasites can result indirectly in reduced abundance of benthic diatoms (here by $8-22 \%$ depending on treatment) as well as positively affect the biomass of a broad group of taxonomically distinct benthic animals. Moreover, in the case of intermediate densities of surfaced cockles, also the otherwise well-defined spatial pattern of abundance seen in the control and 100-cockle treatments (U-shaped, see Figure 1) is broken up. The fact that the occurrence of animals did not follow a similar U-shaped pattern along the experimental transect, evidenced by a general lack of significant block effect regarding biomass, suggests the absence of bottom-up control of the benthic animal community as well as strong top-down control of primary producers. We have emphasized strong because the reduced chlorophyll- $a$ levels in both cockle-treatments may be governed in part by the generally higher abundance of benthic animals in these treatments, either in terms of numbers or biomass (present data): many of the affected species or species-groups are deposit- or selective detritus-feeders that rely on benthic diatoms as a food source.

In contrast, the similar spatial variation in the abundance of benthic diatoms in control and 100-cockle treatments may be governed by minor variation in hydrodynamics and/or exposure time along the experimental transects; both are factors that can influence primary production significantly (see Admiraal, 1984; Pinckney \& Zingmark, 1991; Dade et al., 2001; Jahnke, 2001). Since the density of cockle mimics in the 100cockle-treatment suggests the development of skimmingflow (see Mouritsen \& Poulin, 2005), which mitigates the impact of surface structural complexity on near-seabed hydrodynamics, the control and the 100-cockle treatment are likely to have been exposed to approximately the same hydrodynamics. Because of fewer mimics on the surface in the 30-cockle-treatment skimming flow does not occur, and the surface complexity will significantly change the near-seabed hydrodynamics and hence the pattern of sedimentation (Mouritsen \& Poulin, 2005). A difference regarding spatial variation in abundance of primary producers between the control and the 100-cockle-treatment on the one hand, and the 30-cockle treatment on the other, is therefore not unexpected.

Although we did not measure the primary and secondary production directly, productivity in the present system is most probably highly and positively related to chlorophyll- $a$ (microalgae; see e.g. Admiraal, 1984) and biomass (animals) levels: the organisms all originate from the same source community, and besides the small changes induced by experimental treatments, they have all been exposed to the same set of basic environmental conditions and are therefore likely in the same overall physiological state regardless of treatment.

To our knowledge, the present study is the first field experimental demonstration that parasitism may, indirectly through its behavioural modification of a single community member, significantly impact both the abundance of primary producers and the biomass of a range of secondary producers that likely translates into overall productivity. Because cockle parasitism similarly has been shown to elevate benthic species richness and diversity (Mouritsen \& Poulin, 2005), our results thus provide experimental support that diversity and productivity are linked as expected from theory (e.g. Loreau et al., 2001). An increased focus on such largely unrecognized indirect effects of parasitism may be a fruitful avenue to follow in order to better understand ecosystem functioning in general and the link between diversity and productivity in particular.

We wish to thank Dave Latham and Amy Armstrong for technical assistance. The Danish Natural Science Research Council and the Carlsberg Foundation (K.N.M.) and the Marsden Fund (R.P.) supported the study financially.

\section{REFERENCES}

Admiraal, W., 1984. The ecology of estuarine sedimentinhabiting diatoms. Progress in Phycological Research, 3, 269-322.

Babirat, C., Mouritsen, K.N. \& Poulin, R., 2004. Equal partnership: two trematodes, not one, manipulate the burrowing behaviour of the New Zealand cockle, Austrovenus stutchburyi. Journal of Helminthology, 78, 195-199.

Dade, W.B., Hogg, A.J. \& Boudreau, B.P., 2001. Physics of flow above the sediment-water interface. In The Benthic boundary layer: transport processes and biogeochemistry (ed. B.P. Boudreau and B.B. Jørgensen), pp. 4-43. Oxford: Oxford University Press.

Fridley, J.D., 2001. The influence of species diversity on ecosystem productivity: how, where, and why? Oikos, 93, 514-526.

Jahnke, R.A., 2001. Constraining organic matter cycling with benthic fluxes. In The benthic boundary layer: transport processes and biogeochemistry (ed. B.P. Boudreau and B.B. Jørgensen), pp. 302-347. Oxford: Oxford University Press.

Loreau, M. et al., 2001. Biodiversity and ecosystem functioning: current knowledge and future challenges. Science, New Kork, 294, 804-808.

McCann, K.S., 2000. The diversity-stability debate. Nature, London, 405, 228-233. 
Minchella, D.J. \& Scott, M.E., 1991. Parasitism: a cryptic determinant of animal community structure. Trends in Ecology and Evolution, 6, 250-254.

Mouritsen, K.N., 2002. The parasite-induced surfacing behaviour in the cockle Austrovenus stutchburyi: a test of an alternative hypothesis and identification of potential mechanisms. Parasitology, 124, 521-528.

Mouritsen, K.N., Mouritsen, L.T. \& Jensen, K.T., 1998. Change of topography and sediment characteristics on an intertidal mud-flat following mass-mortality of the amphipod Corophium volutator. Fournal of the Marine Biological Association of the United Kingdom, 78, 1167-1180.

Mouritsen, K.N. \& Poulin, R., 2002. Parasitism, community structure and biodiversity in intertidal ecosystems. Parasitology, 124, S101-S117.

Mouritsen, K.N. \& Poulin, R., 2005. Parasite boosts biodiversity and changes animal community structure by trait-mediated indirect effects. Oikos, 108, 344-350.
Naeem, S. \& Wright, J.P., 2003. Disentangling biodiversity effects on ecosystem functioning: deriving solutions to a seemingly insurmountable problem. Ecology Letters, 6, 567-579.

Pinckney, J. \& Zingmark, R.G., 1991. Effects of tidal stage and sun angles on tidal benthic microalgae productivity. Marine Ecology Progress Series, 76, 81-89.

Siegel, S. \& Castellan, N.J. Jr, 1988. Nonparametric statistics for the behavioural sciences, 2nd edn. New York: McGraw-Hill.

Thomas, F. \& Poulin, R., 1998. Manipulation of a mollusc by a trophically transmitted parasite: convergent evolution or phylogenetic inheritance? Parasitology, 116, 431-436.

Thomas, F., Renaud, F., De Meeus, T. \& Poulin, R., 1998. Manipulation of host behaviour by parasites: ecosystem engineering in the intertidal zone? Proceedings of the Royal Society B, 260, 349-352.

Submitted 23 March 2005. Accepted 20 January 2006. 